\title{
A musealização de um passado ambíguo: 0 caso dos lugares de isolamento compulsório, entre afetos privados e a transmissão de uma memória heroica da saúde
}

\section{The musealization of an ambiguous past: The case of places of compulsory isolation, between private affections and the transmission of a heroic memory of health}

Recebido em: 10/01/2019

Aceito em: 23/01/2019

Daniele Borges Bezerra ${ }^{1}$ Juliane conceição Primon Serres ${ }^{2}$

\section{Resumo:}

A transmissão do passado está condicionada à criação de dispositivos memoriais que estruturam as memórias na forma de narrativas. Assim, quando as memórias são investidas de valor patrimonial, migram do universo individual para o espaço público. Entretanto, devido ao aspecto delicado de algumas memórias, defrontamo-nos com um dilema situado entre o compromisso ético de seu reconhecimento e as formas de transmissão do passado, que pode ser incômodo. Discutiremos - reconhecimento patrimonial de lugares marcados por memórias difíceis: as antigas colônias de isolamento sanitário, criadas para o isolamento da lepra. Para isso, tomaremos como estudo de caso o Hospital-Colônia Itapuã (RS). Analisaremos o modo como as memórias do lugar são acionadas pelo dispositivo de memória criado no hospital e qual a opinião dos antigos moradores sobre esses dispositivos.

Palavras-chave: memórias difíceis; patrimônio ambíguo; narrativas domesticadas.

\section{Abstract:}

\footnotetext{
${ }^{1}$ Doutoranda no Programa de Pós-Graduação em Memória Social e Patrimônio Cultural- Centro de Ciências Humanas- UFPel. E-mail: borgesfotografia@gmail.com

2 Doutora em História pela Universidade do Vale do Rio dos Sinos. Coordenadora do Programa de PósGraduação em Memória Social e Patrimônio Cultural- UFPel. E-mail: julianeserres@gmail.com
} 


\begin{abstract}
The transmission of the past is conditioned to the creation of memory devices that structure the memories in the form of narratives. Thus, when memories are invested with patrimonial value, they migrate from the individual universe to the public space. However, due to the delicate aspect of some memories, we are faced with a dilemma between the ethical commitment of its recognition and the forms of transmission of this past, which can be nuisance. We will discuss the patrimonial recognition of places marked by difficult memories: the old colonies of sanitary isolation, created for the isolation of the leprosy. For this, we will take as case study the HospitalColônia Itapuã (RS). We will analyze how memories of the place are triggered by the memory device created in the hospital and what is the opinion of local ancients residents.
\end{abstract}

Key- words: Difficult memories; ambiguous heritage; domesticated narratives.

\section{Hospital-Colônia Itapuã: Velhos e novos usos do espaço}

O Hospital Colônia Itapuã ( $\mathrm{HCl}$ ) foi inaugurado na década de 1940 no governo de Getúlio Vargas, como um dos dispositivos profiláticos que integravam a política nacional de combate à lepra. A doença que passou oficialmente a ser denominada hanseníase no Brasil em $1995^{3}$, é provocada pelo mycobacterium leprae, bacilo que foi descoberto pelo norueguês Armauer Hansen em 1873.

Embora a descoberta do "poder terapêutico das sulfonas" (CARVALHO, 2012 p.125) estivesse por ocorrer nos Estados Unidos em 1941, no Brasil os medicamentos à base de sulfonas só começaram a ser testados em 1944, de modo que, não havendo nenhuma perspectiva de cura os pacientes eram encaminhados para os hospitais-colônia onde permaneciam por tempo indeterminado. Então, a principal medida sanitária promovida pelo Estado brasileiro, que seguia o modelo norueguês, era o isolamento como profilaxia para atenuar o contágio e a disseminação da doença entre a parcela saudável da população, uma vez que o tratamento a base de chaulmoogra, diponível na época, era paliativo.

\footnotetext{
${ }^{3} \mathrm{~A}$ alteração do nome foi pensada para reduzir o estigma associado à doença e facilitar a procura por tratamento. Isso ocorreu com a Lei 9.010/1995.
} 
O espaço do $\mathrm{HCl}$ abrange uma área de 1.251 hectares e está localizado a $48 \mathrm{~km}$ de Porto Alegre (RS), na região de Viamão, onde faz divisa com a Lagoa Negra ${ }^{4}$, o Rio Guaíba e o Parque Estadual de Itapuã ${ }^{5}$, barreiras topográficas que auxiliavam no processo de isolamento geográfico. Criado na forma de uma microcidade, seguindo o projeto da "Leprosaria Modelo de Santo Ângelo (SP), projetada pelo arquiteto Adelardo Caiuby, o $\mathrm{HCl}$ possuía prefeitura, cine teatro, cadeia, três igrejas, padaria, sapataria, enfermaria, cemitério, forno de incineração, tambo, etc... E, no final da década de 1940, mais de mil doentes haviam sido internados no $\mathrm{HCl}$ (SERRES, 2009). Assim, cientes do ônus que o número expressivo de pacientes representava ao Estado, os sanitaristas haviam criado colônias de isolamento autossustentáveis, que funcionavam como "instituições totais" (GOFFMAN, 1988, p.20), criadas para proporcionar aos internados uma rotina independente do mundo exterior, "semelhante à dos sãos, com distrações, conforto e trabalho" (MAURANO, 1944, p. 140).

Nesse ínterim, os moradores eram incentivados a trabalhar dentro das colônias, recebendo valores irrisórios, conforme se lê nas narrativas abaixo ${ }^{6}$ :

\begin{abstract}
Eu trabalhava no laboratório, com o Dr. Jurandir, porque tinha laboratório tinha tudo aqui. Eu passava exame pra ele. Naquela época pra fazer exame de sangue se furava o dedo. Eu tinha um medo daquilo. Então eu trabalhava com ele e com o Dr. Ari. Tiravam as fichas, porque era muita gente. Tinha umas mil pessoas naquela época. Tinha dois dermatologistas, dois dentistas e mais dois clínicos. Nós éramos duas gurias, mais outra senhora. A outra trabalhava com o dentista, então nós passava a manhã inteira lá. [vocês recebiam pelo trabalho?] É, era uma coisinha, nem meio salário [...] Era média de trinta, outras vezes era cinquenta. Era pouquinho [...] (Informação verbal ${ }^{7}$ ).
\end{abstract}

A fala do Sr. Carlos também elucida a natureza do trabalho e a manutenção de uma autonomia relativa no interior das colônias:

É, era apertado. Mas eu também trabalhava. Na manutenção, elétrica, hidráulica. Não dava pra fazer quase nada [com o dinheiro], mas sempre ajudava. Depois,

\footnotetext{
${ }^{4}$ Percebe-se na escolha do terreno resquícios das estratégias iniciais pautadas pelo modelo draconiano, ou seja, locais de difícil acesso, isolados dos grandes centros, onde a própria geografia do local dificultava as tentativas de fuga, geralmente ilhas.

${ }^{5}$ Reserva ambiental que abriga diversas famílias indígenas guaranis. A aldeia guarani Pindó Mirim, vinculada ao território desde 1960, aproximadamente, e a comunidade de japoneses, localizada no entorno do $\mathrm{HCl}$ desde 1975 , são comunidades que mantiveram algum contato com o local, através da utilização do serviço ambulatorial oferecido dentro do $\mathrm{HCl}$ até o ano 2011.

${ }^{6}$ Respondendo à critérios éticos em pesquisa os interlocutores serão apresentados por meio de pseudônimos, mesmo tendo consentido com a exposição dos dados fornecidos durante a pesquisa.

${ }^{7}$ Narrativa da moradoradora do $\mathrm{HCl}$, identificada pelo pseudônimo de Alice, em entrevista concedida à Daniele Borges Bezerra em jan. de 2017.
} 
qualé a diretora que entrou que deu aumento pra nós? Cem reais, aí... Bah, aí era bastante. (Informação verbal ${ }^{8}$ )

Alice e Carlos são um dos casais que se conheceram dentro do HCl. Portanto, dentro dessas comunidades hospitalares, os habitantes eram estimulados ao casamento, desde que ambos fossem portadores da doença. Os filhos nascidos da união entre asilados, eram separados no momento do nascimento e a recomendação era de que fossem mantidos sob vigilância até a idade de 5 a 6 anos. Embora a hereditariedade da doença não fosse comprovada, nem o aleitamento, nem o contato físico eram permitidos, já que os modos de transmissão da doença nunca foram muito bem estabelecidos ${ }^{9}$. Assim, o Modelo tripé, como ficou conhecido, contava com três instituições: o dispensário ${ }^{10}$, o leprosário e o preventório ${ }^{11}$, cada uma com uma atribuição própria, projetadas pra desempenhar funções complementares. Fora dos limites da colônia a fiscalização de casos suspeitos de hanseníase e a apreensão compulsória eram exercidas por uma polícia sanitária. Nesse sentido, para evitar o isolamento, os doentes "buscavam ocultar a sua enfermidade. Contudo, quando eram descobertos pelos serviços de saúde, o asilamento era inevitável" (SERRES; BORGES, 2014, p.3). No interior das colônias os cargos, até mesmo os de guarda e delegado, eram exercidos pelos próprios moradores, e essa posição destacada de poder delegava aos eleitos uma posição privilegiada em relação aos demais, uma espécie de "ganho secundário" (GOFFMAN, 1988, p.20) alcançado com o isolamento compulsório.

Com a descoberta da primeira medicação efetiva no tratamento da hanseníase, em 1941, o cenário terapêutico da doença foi alterado. No $\mathrm{HCl}$, a utilização da sulfona foi introduzida em 1948, o que resultou na remissão dos sintomas, impedindo a progressão das sequelas e interrompendo a transmissão do bacilo. Assim, na década de 1960, motivados pelo discurso de cura, e pelas recomendações extraídas do VII Congresso Internacional de leprologia, ocorrido no Japão em 1958, o isolamento passou a ser questionado no Brasil. Passaram-se mais duas décadas até que o fim do isolamento compulsório se efetivasse. No

\footnotetext{
${ }^{8}$ Narrativa do morador do $\mathrm{HCl}$, Sr. Carlos, em entrevista concedida à Daniele Borges Bezerra em jan. de 2017. ${ }^{9}$ Sabe-se que a transmissão se dá por contato prolongado, em pessoas que não são naturalmente imunes ao Bacilo de Hansen, por meio das gotículas salivares ou fluídos nasais de pessoas que se encontrem em fase de transmissão da doença. Nos dias de hoje, com o tratamento poliquimioterápico (PQT), o bacilo perde seu poder de contágio já partir da primeira dose do remédio.

${ }^{10}$ Os dispensários eram a porta de entrada para o tratamento, uma estrutura estratégica de vigilância, que atraia os doentes que precisavam de tratamento.

11 Os Preventórios eram locais, a cargo das ordens religiosas, que ficavam afastados dos hospitais-colônia. Apesar de prever que as crianças permanecessem "sob vigilância durante 5 a 6 anos" (SOUZA-ARAUJO, 1956, p.377), sob o cuidado das freiras, a maioria só saia quando algum tutor se responsabilizava por eles, ou ao atingir a idade de 14 anos.
} 
entanto,o Decreto Federal n. 968/1962 flexibilizou o fluxo de entradas e saídas nos hospitais-colônia e representou o começo da desconstrução da política de isolamento.

Com o fim do isolamento, o $\mathrm{HCl}$ desenvolveu o projeto de um Centro Agrícola de Reabilitação (CAR), para onde foram enviados na década de $1970^{12}$, pacientes psiquiátricos crônicos ${ }^{13}$ transferidos do Hospital Psiquiátrico São Pedro (HPSP). Tal transferência ocorreu como parte das políticas sanitárias delineadas pela Reforma Psiquiátrica, que ganhava força a partir da década de 1970 e tinha como principal objetivo a humanização hospitalar, com o progressivo fechamento dos hospitais psiquiátricos, a desinstitucionalização e a reintegração social de pacientes isolados em manicômios (BASAGLIA; 1968 SARACENO, 1999; PITTA, 1996). Conforme depoimento do funcionário público Jairo Antão ${ }^{14}$, filho de antigos moradores isolados pela hanseníase, os pacientes psiquiátricos enviados para o CAR não estavam, necessariamente, passando por um processo de reintegração social como o movimento pela Reforma psiquiátrica apregoava naquele período:

\begin{abstract}
Eu trabalho aqui há mais de três décadas, cheguei aqui eu era bem guri. No início eram todos jovens, como eu era. E hoje já estão numa idade bem mais avançada. Eles eram obrigados a trabalhar no Itapuã, na laborterapia. O paciente mental tinha que trabalhar. Ele era forçado a trabalhar. Chegava no quarto, acordava o paciente se ele não queria ele era agarrado, medicado e até contido. Isso acabou, graças a Deus tudo isso acabou. (informação verbal ${ }^{15}$ ).
\end{abstract}

Assim, o que vimos acontecer em meio às propostas de alteração do modelo de atenção, foi a reutilização das antigas-colônias, distantes dos grandes centros, como resposta à pressão pelo esvaziamento dos hospitais psiquiátricos. Desfecho semelhante ocorreu na Europa do século XIV, quando o fim da endemia da lepra cedeu espaço à loucura - que representava um risco simbólico de contaminação - e os lazaretos transformaram-se em locais para isolar loucos (FOUCAULT, 2000). Esses novos usos dados ao $\mathrm{HCl}$ não deixam de reforçar o caráter de exclusão e o estigma associados ao espaço. Conforme afirma Michael Ignatieff esses locais, entendidos como "instituições totais" (Cf. GOFFMAN, 2003) "[...] produzem seus efeitos na sociedade através do peso

\footnotetext{
${ }^{12} \mathrm{Em}$ janeiro de 2017, com o número reduzido de moradores, houve nova transferência de pacientes até então asilados no HPSP.

${ }^{13}$ Todos homens em condições de trabalho.

${ }^{14} \mathrm{Jairo}$ tem uma relação muito íntima com o local, porque é filho de pessoas que passaram pelo isolamento compulsório no $\mathrm{HCl}$. Sua relação com o espaço é longa, desde a infância e, desde o início da vida adulta atua como parte da equipe de funcionários, dedicando-se aos pacientes psiquiátricos.

${ }^{15}$ Narrativa do funcionário Jairo Antão, durante visita guiada ocorrida no Memorial $\mathrm{HCl}$ em 08 de mar. de 2016.
} 
mítico e simbólico de suas paredes no mundo exterior" (IGNATIEFF, 1987, p.188), servindo como arcabouço para o imaginário do confinamento.

Nessa perspectiva, o asilamento em uma "instituição total" cumpria não apenas uma função de isolamento físico, mas também agia como um mecanismo de equilíbrio das tensões sociais, afastando do meio social produtivo aqueles que representassem uma ameaça simbólica, ou que não acompanhassem o ritmo da sociedade de consumo. Ainda, por mais humanas que possam se constituir as instituições de caráter asilar, estas se caracterizam, ainda hoje, como lugares de invisibilidade.

Enquanto lugar de isolamento compulsório, o $\mathrm{HCl}$ tornou-se um ícone da história da lepra no RS e, ainda hoje, a maioria das pessoas que sofreram com a política de isolamento compulsório, carrega consigo o estigma da doença. Num primeiro momento, os danos provocados pelo isolamento causaram um sentimento de "desenraizamento" (RADLEY, 1994; HALBWACHS, 1990) familiar, comunitário, social e laboral que teve consequências sobre as identidades. Os portadores do Mal de Hansen eram socialmente mal vistos e passavam a introjetar esses estigmas, difíceis de desvincular de si, antes mesmo da internação, mas ser constrito ao isolamento soava como um tipo de condenação que provocou marcas simbólicas que permaneceram mesmo com o fim do isolamento compulsório na década de 1980. O medo de ser identificado como um "leproso" esteve presente, e ainda está, em muitos ex-moradores, como se a sociedade pudesse a qualquer momento, indicar-Ihes as cicatrizes invisíveis. Marcas subjetivas que talvez só passem depois de se tornarem muito claras, até que não haja nada de sombrio nas memórias que envolvem a doença. Não obstante, as sequelas visíveis não são causa de vergonha ou sofrimento, não há vergonha em ter sido afetado pela doença numa época em que não havia cura, essa fase foi superada, o receio é defrontar-se novamente com o preconceito.

Atualmente, em estado de quase ruína, a grande estrutura do $\mathrm{HCl}$ encontra-se num estado limiar entre o seu reconhecimento como bem patrimonial e a atribuição de novos usos. O lugar mantém o seu funcionamento vinculado ao setor da saúde pública, embora, os serviços prestados sejam predominantemente de caráter asilar. De modo que, o $\mathrm{HCl}$ serve de residência a 12 idosos, que foram isolados na juventude com diagnóstico de hanseníase e, apesar de curados, perderam seu vinculo social com as comunidades de origem, além de 40 pacientes psiquiátricos, crônicos, provenientes do HPSP. Assim, apesar da dimensão dolorosa do passado que marca o lugar, para alguns ainda presente, e dos ideais reformadores que nos inclinam a pensar a inclusão acima de tudo, o lugar tornou-se um 
refúgio para estes dois grupos de outsiders, nessa fase da vida em que almejam serenidade.

\section{Comunidades afetivas fundadas por um marco doloroso}

A então temida lepra, hoje chamada hanseníase, marca a identidade de milhares de pessoas que tiveram o diagnóstico da doença e o isolamento compulsório como pontos de contato para a criação de memórias compartilhadas. O sofrimento inicial, provocado pela ineficácia terapêutica (no período em que a cura era desconhecida), pelo isolamento compulsório, pelo preconceito, e por abusos físicos ou emocionais, foi aos poucos cedendo espaço para novas formas de sociabilidade dentro das colônias. De modo que, ao configurar-se como uma experiência compartilhada de longa duração, estes lugares passaram a constituir-se como um refúgio, o cenário ideal para o surgimento de comunidades afetivas.

Essa nova forma de sociabilidade criada no interior das colônias, configura o que Alice Cruz (2006, p.68) chamou de uma "comunidade espacialmente determinada" (CRUZ, idem, p.68). O espaço possui uma posição primordial na compreensão dessas comunidades, uma vez que são formadas a partir da delimitação de tais fronteiras. Entretanto, a partilha da vida privada num espaço compartilhado, que demarca uma experiência dolorosa comum, nos permite observar a constituição de comunidades afetivas, que acionam uma "micropolítica da emoção" (REZENDE; COELHO, 2010, p.78) em que "as emoções surgem perpassadas por relações de poder, estruturas hierárquicas ou igualitárias, concepções de moralidade e demarcações de fronteiras entre os grupos sociais" (idem).

Assim, ao identificarem-se como "companheiros de infortúnio" (GOFFMAN, 1988 p.46), tanto no que se refere à experiência de adoecimento, como em referência ao estigma, e à obrigatoriedade do isolamento, os membros do grupo passam a comportar-se como uma comunidade que possui "uma ordem social própria" (IGNATIEFF, 1987 p. 190). Mas, dada a condição ambivalente da vinculação do indivíduo com o grupo e com os lugares, numa permanência que está atrelada à doença como categoria indesejada, "é compreensível que ocorram oscilações no apoio, identificação e participação que têm entre seus iguais" (idem p.47).

Para Joel Candau os atos de memória apoiados em marcos memoriais partilhados por um grupo "podem delimitar uma área de circulação de lembranças, sem que por isso 
seja determinada a via que cada um vai seguir" (CANDAU, 2011, p. 35). Portanto, embora a experiência do isolamento tenha sido pautada a partir de um modelo comum de sociabilidade dentro dos hospitais-colônia, não é possível afirmar que os pontos de contato sejam suficientes para uma uniformidade das interpretações sobre o passado. Pois, enquanto para alguns o fato de ter desenvolvido a doença, por si só já representava uma ruptura com a vida pregressa, para outros o isolamento e, não a doença, é identificado na origem do sofrimento partilhado. Isso também ocorre em relação ao significado que o hospital assume no presente: para uns o lugar ainda representa a figura do trauma vivido e a fissura com o mundo exterior, para outros representa um lugar de proteção, o palco onde se desenrolaram os anos da juventude.

Portanto, podemos falar em comunidade afetiva, sem esquecer que o isolamento foi "vivenciado de maneiras distintas" por cada pessoa, de acordo com suas trajetórias de vida (SERRES, 2009, p.15), pois, conforme Erving Goffman, o mundo social do internado "é subjetivamente vivido por ele" (GOFFMAN, 2003, p.8) e, neste caso, foi determinado pelo impacto da doença, suas expectativas de futuro, pela condição de possibilidade de criar novos vínculos afetivos, e pela capacidade de adaptar-se a uma situação nova como a que estava colocada.

Assim, ao curso de aproximadamente 70 anos, muitos moradores identificam o lugar como a sua casa, outros o identificam como um "canto abençoado" (Informação verbal ${ }^{16}$ ), um lugar onde estão ancoradas as memórias da juventude, mesmo que o sofrimento esteja presente em muitos de seus relatos, relacionado à ruptura inicial que o isolamento promoveu. Mas essa forte vinculação afetiva com o lugar não é apenas negativa, existe com o lugar uma relação ambígua de nostalgia em relação à vida que ali se desenvolveu e, também, de irremediável, concernente à experiência de adoecimento no contexto histórico, político, e social, que determinou que a vida fosse reconduzida na direção de uma comunidade que nasceu a contrapelo, a partir do isolamento forçado. Além dos moradores, há relatos de funcionários, trabalhadores da saúde e alguns filhos de ex-internos que narram o lugar com nostalgia, e o consideram a partir de um ponto de vista afetivo, como um suporte para as memórias individuais e coletivas. Memórias situadas no tempo e no espaço, emolduradas por práticas sociais que não deixaram de acontecer no isolamento, como os já

\footnotetext{
${ }^{16}$ Expressão utilizada pela moradora Leonora em conversa estabelecida no $\mathrm{HCl}$ em jan. de 2017.
} 
mencionados casamentos, nascimentos, trabalho e morte, que hoje permitem lembrar eventos que marcaram as suas trajetórias de vida (HALBWACHS, 2004, p.89).

Então, se o internamento compulsório se configura como um "[...] marco espacial, temporal e, mais geralmente, social" (HALBWACHS, 2004, p.125) que demarcou uma violência simbólica diante da política de segregação, o reconhecimento das memórias no presente, está imbricado num processo de "localização das lembranças" (HALBWACHS, 2004, p.144) que têm no espaço (onde), no tempo (quando), e na afiliação a um grupo (família, amigos, moradores, etc...) os "marcos sociais" (HABWACHS, idem, p.141-155) que nos permitem escapar dos silenciamentos produzidos pelos discursos oficiais. Nesse sentido, a espacialidade dos lugares e a narrativa dos grupos se apresentam como veículos profícuos de acesso e transmissão do passado. E é por isso que as narrativas dos dispositivos intencionais de memória, museus e memoriais, criados nestes lugares nos informam sobre as ideologias envolvidas no processo de administração do passado, com a criação de memórias apaziguadas ou com a ativação do espaço como um meio de contaminação memorial.

\section{O legado cultural da política de isolamento compulsório: Um patrimônio ambíguo}

A dilatação do conceito de patrimônio, que se torna menos seletivo e mais democrático, a partir do final do séc. XX, nos permite pensar a dimensão ética da memória como instrumento de projeção do passado em direção ao futuro, não apenas como reserva para as gerações que virão, mas como recurso para a legitimação das reivindicações de direitos no tempo presente.

O processo de preservação da memória institucional do $\mathrm{HCl}$ teve início com a criação do Centro de Documentação e Pesquisa (CEDOPE) em 1999, na antiga casa das irmãs franciscanas ${ }^{17}$. O espaço:

[...] além das documentações textual, iconográfica e bibliográfica, previa um trabalho de recuperação da memória dos moradores do hospital, através de um projeto de história oral. Parte dessas entrevistas foram usadas na exposição sobre os 60 anos da Colônia Itapuã, comemorados em 2000, a exposição contava um pouco da história do hospital e seus moradores. (SERRES, BEZERRA, no prelo).

\footnotetext{
${ }^{17}$ Projeto desenvolvido pela historiadora Arselle Andrade da Fontoura e um grupo de alunos da Universidade Federal de Santa Maria.
} 
O CEDOPE funcionou entre os anos 1999 e 2001 e, após esses primeiros anos, passou por períodos de fechamento. Em 2005, um projeto em parceria com o Museu de História da Medicina do Rio Grande do Sul tentou reativá-lo por iniciativa de algumas pessoas, mas com a saída destes profissionais, a reativação não teve sequência. Em 2007, ocorreu uma nova tentativa de reativação do CEDOPE, motivada pelo Projeto Global Sobre a História da Hanseníase, promovido pela International Leprosy Association (ILA), com recursos da OMS e da Nippon Foundation, com apoio da Universidade de Oxford, um projeto que "fomenta a guarda e conservação de documentos importantes para o entendimento da história da doença e seus efeitos sociais" (MORHAN, 2010, p.5).

Com relação ao reconhecimento oficial do $\mathrm{HCl}$ pelos órgãos do patrimônio, em 2010 foi tombada pelo Instituto do Patrimônio Histórico e Artístico do Estado do Rio Grande do Sul (IPHAE- RS), a Igreja Evangélica Luterana e a área caracterizada como entorno (300 metros), que engloba parte do conjunto hospitalar. O registro de seu inventário destaca a qualidade arquitetônica e a representatividade do bem, como última obra do arquiteto alemão Theodor Alexander Josef Wiederspahn. Mas, além de informar sua localização dentro do antigo leprosário o inventário justifica, apenas de modo superficial, a importância cultural dessa igreja, sem validar a relevância cultural do conjunto e a dimensão imaterial que ele ancora. Além disso, com a exposição às ações do tempo e a ausência de ações preventivas ou de manutenção, o desuso da igreja, e a condição de isolamento do conjunto contribuem para o estado de degradação do bem. Para agravar o caso, as negociações entre o IPHAE e os escritórios de arquitetura não levaram a um acordo até o momento (informação verbal ${ }^{18}$ ). Notamos no prédio, a ausência de elementos arquitetônicos originais, como o assoalho e a cúpula, além da presença de infiltrações que viabilizaram o crescimento de vegetação nas paredes e no teto.

O arruinamento, deste e outros prédios, não passa despercebido, mas está integrado na dinâmica da vida da colônia e presente na narrativa de moradores e funcionários da colônia. A interlocutora Suzana, por exemplo, que presta serviços autônomos a alguns moradores idosos da colônia, afirma que evita passar na mesma calçada da igreja, por medo que o prédio desabe. Esse risco iminente também está claro na fala de Leonora (80 anos) que chegou ao $\mathrm{HCl}$ com 27 anos, quando ela diz: "A crente aqui

\footnotetext{
${ }^{18} \mathrm{~A}$ informação foi fornecida pela então diretora do IPHAE Miriam Sartori Rodrigues, por comunicação estabelecida via correio eletrônico em 10 de mai.de 2017.
}

Revista Memória em Rede, Pelotas, v.11, n.20, Jan./Jun.2019 - ISSN- 2177-4129 
ta caindo, é um pecado. Até quando caiu essa garagem aqui do Pedro, lá de cima eles escutaram e acharam que era a igreja que tinha caído." (Informação verbal ${ }^{19}$ ).

Nesse contexto, a abertura do processo ${ }^{20}$ para o tombamento do conjunto do $\mathrm{HCl}$ pelo então diretor do IPHAE/RS, Eduardo Hahn, em 2013, e a criação do Memorial $\mathrm{HCl}$ em 2014, indicam uma movimentação recente no que se refere ao reconhecimento patrimonial desses lugares de isolamento, em âmbito nacional. Mas, embora as atitudes preservacionistas no $\mathrm{HCl}$ indiquem a presença do lugar nesse processo mais amplo de patrimonialização de antigos leprosários - uma patrimonialização em processo - como ocorre em outros estados brasileiros e no mundo, percebe-se que a dimensão imaterial da memória está em risco, sobretudo se considerarmos que os últimos a testemunhar a experiência do isolamento compulsório no lugar, hoje são idosos.

Trata-se, num primeiro momento, de uma memória perpassada por forças e ações políticas, no campo da saúde pública no Brasil que, durante duas décadas tiveram no isolamento sanitário o único tratamento para o problema da lepra. $\mathrm{O} \mathrm{HCl}$ é, neste sentido, um patrimônio da saúde que permite acessar a memória das tecnologias de combate à doença. Por outro lado, ao considerarmos a memória de quem viveu o isolamento compulsório, toca-se numa memória dolorosa, geralmente acompanhada pelo estigma da doença, e pela limitação social que a reclusão forçada causou. Uma memória que extrapola o campo da saúde pública.

Devido à característica incômoda dessas memórias e ao aspecto negativo associado à doença, lugares como os leprosários não foram por muito tempo reivindicados como patrimônio. Pelo contrário, há uma opinião ${ }^{21}$ de que lugares marcados pelo sofrimento, pelo estigma e pelo abuso de poder, deveriam ser destruídos, fazendo desse gesto performático, um ato catártico e simbólico de destruição da existência negativa e obscura do lugar, e, por extensão, das politicas que o geraram. Entretanto, é a própria presença incômoda de tais lugares, que sinalizam valores negativos, que precisa ser conservada para nos sensibilizar sobre o passado e nos preparar para o futuro.

Além disso, apesar do sofrimento relacionado ao passado, traços de experiências compartilhadas nestes lugares demonstram a reinvenção de pessoas que chegaram como

\footnotetext{
${ }^{19}$ Informação fornecida pela interlocutora Leonora à Daniele Borges Bezerra, no $\mathrm{HCl}$, em jan. de 2017.

20 O processo $n^{\circ}$ 1680-1100/13-1 foi encerrado em agosto de 2017, pela diretora em exercício no IPHAE, Renata Horowitz.

${ }^{21}$ Referimo-nos à ideologia militante dos profissionais que atuam a favor da desinstitucionalização e do fim do modelo hospitalocêntrico
} 
doentes e hoje vivem como moradores. Portanto, são lugares que também servem como suporte de afetos positivos, o que faz deles um patrimônio ambíguo que é foco da preocupação dos antigos moradores. Nesse sentido, a preservação do espaço e de sua memória, se confunde com a preservação da trajetória de vida de cada morador. Como é possível observar na fala de Leonora:

O lugar, mas eu morro de tristeza de ver essas coisas caindo tudo, a beira das casinhas tão caindo e ta tudo tomado de cupim. E os pavilhões a gente olha os telhado caindo, tudo, tudo, tudo. Era lindo isso aqui, era lindo, lindo, lindo mesmo, no tempo que tinha bastante gente, né. As casinhas eram tudo cheia. Os pavilhão, os quartos eram de dois, três, cada quarto, de tanta gente que tinha e hoje em dia ta tudo caindo, sem nada. (risos). [...] E vai se demolir tudo, não fazem manutenção, nem nada.E diz que não tem verba pra isso[...]. A cancha também ta caindo, né? Tudo ta caindo. (Informação verbal ${ }^{22}$ ).

O mesmo sentimento de abandono, e fim de vida da instituição, é manifestado pelo Sr. Carlos, morador do $\mathrm{HCl}$ há 62 anos: "Como é que o Estado diz que não tem dinheiro, com todos esses prédios aqui se perdendo? Apodrecendo. Tudo caindo. Todas essas casas caindo". (Informação verbal|23). Em conversa com outro morador, o Sr. Pedro, ao falarmos sobre a sua experiência de vida no lugar ele começa dizendo que mora no local há 51 anos e que deixou um mundo pra trás, apesar dessa ruptura ele diz: "É, enquanto durou, foi bom. Agora, também, ta quase terminando, né? Tem pouco pessoal. Tem pouca gente. Uns foram embora, outros faleceram" (Informação verbal ${ }^{24}$ ). E quando pergunto sobre os destinos prováveis do lugar ele responde:

Eu acho que vai terminando, vai terminar, né? Mas eles tão trazendo... Talvez fique pra psiquiatria. Termina o pessoal da hanseníase, que tem pouco já aqui, né, e ficam os que vêm do São Pedro, trouxeram muitos. Do fundo pra lá ta o São Pedro, né. O São Pedro é que ta usando. (Informação verbal ${ }^{25}$ ).

Outra moradora, Valdete, que mora no $\mathrm{HCl}$ há 60 anos, diz:

Olha, se não vier mais gente da hanseníase eles vão mudar pra outras coisas. É o que eu tenho sentido. Já ouvi falar de tudo: "Ah, a enfermaria pequena, só com seis pessoas, a gente podia mudar eles pra um lugar mais alegre." Eu digo, aonde? Porto Alegre eu não quero. Pode ser aqui mesmo, né? O que eu gostaria de ter era uma

\footnotetext{
22 Narrativa de Leonora, durante entrevista narrativa realizada com Daniele Borges Bezerra em jan.de 2017.

${ }^{23}$ Narrativa de Carlos, durante entrevista narrativa realizada com Daniele Borges Bezerra em jan. de 2017.

24 Narrativa de Pedro, durante entrevista narrativa realizada com Daniele Borges Bezerra em jan.de 2017

${ }^{25}$ Narrativa de Pedro, idem.
} 
casa lá fora, e um marido e os filhos, mas não tive, então agora [...]. (Informação verbal2 $\left.^{26}\right)$.

Nesse outro trecho da narrativa do Sr Carlos, o interlocutor expressa a relação afetiva estabelecida com o lugar pelo ato de habitar, mas também os sentimentos contraditórios no tocante a situação ambígua que perpassa a noção de propriedade.

\begin{abstract}
A casa ta se quebrando toda. Ta demolindo tudo. Rachada, e cupim. E a gente pensa - eles aí não reformam mais nada - então a gente tem que dar material... Eu não vou investir pra deixar pra eles depois. Não sei como vai ser isso. Como é que a gente vai, já na idade que ta, investir numa casa que vai ficar aí depois? Eu não sei. E uma casinha boa. E, a gente sente. Ver as coisas, a gente tem as coisinhas da gente.Tem fruta aí de tudo que é espécie de fruta. A gente se apega, sim. Se caso eles apertarem pra sair, que vão terminar, a gente pode morar até na casa da praia $^{27}$. Como é que eles vão ficar com esse patrimônio, tudo aí, três, quatro paciente. Eu acho que não vão deixar, né. Quanta terra que eles tem aí. (Informação verbal $^{28}$ )
\end{abstract}

Nesse contexto, embora o reconhecimento oficial do conjunto não tenha se efetivado até o momento, existe por parte dos moradores, um desejo manifesto pela preservação desse patrimônio que já foi o marco temporal de uma experiência de sofrimento, mas hoje simboliza as relações de uma vida de afetos compartilhados, e um lugar de ancoragem da própria identidade.

\title{
Memorial HCl: Um dispositivo memorial criado entre silentes
}

A criação do Memorial $\mathrm{HCl}$ em 2014, indica o desejo de preservar os testemunhos materiais deste patrimônio, num momento em que a função "hospitalar" chega a seu fim. Também reflete uma movimentação no que se refere ao reconhecimento patrimonial desses lugares de isolamento, em âmbito nacional. Note-se o caso paulista onde seis processos foram discutidos em conjunto sob o tema "colônias de tratamento da lepra" (UPPH, 2015) resultando no tombamento em bloco pelo órgão de patrimônio estadual (Condephaat).

Localizado na antiga casa das freiras franciscanas, o memorial é aberto de acordo com uma escala de agendamento de grupos, e apresenta aos visitantes um acervo variado,

\footnotetext{
${ }^{26}$ Narrativa da moradora Valdete, em entrevista narrativa realizada com Daniele Borges Bezerra em jan. de 2017.

27 Após o fim do isolamento, muitos moradores compraram casas na comunidade do entorno com o valor retroativo referente à indenização aprovada pela Lei $11.520 / 2007$, que institui o pagamento de uma pensão mensalpara as pessoas que passaram por internação ou isolamento compulsório até o ano de 1986

${ }^{28}$ Narrativa de Carlos, durante entrevista narrativa realizada com Daniele Borges Bezerra em jan. de 2017.
} 
composto por objetos antigos que, quase sempre ${ }^{29}$ remetem à vida na colônia, uma vida que se confunde com a própria rotina hospitalar. Dentre eles há: equipamentos cirúrgicos, e de laboratório, documentos escritos, fotografias antigas cedidas pelos moradores, fotografias atuais de casais, feitas para ilustrar os casamentos na colônia, moldes para calçados que se adaptavam às amputações provocadas pela doença, máquina para esterilizar objetos manipulados pelos pacientes, máquina de costura, instrumentos utilizados na agricultura, instrumentos da antiga padaria, vidros de remédio, mesas de bilhar, etc, objetos que ao serem distribuídos em salas temáticas, recriam dimensões da vida ordinária num isolamento sanitário de longa permanência.

O Memorial $\mathrm{HCl}$ foi criado por iniciativa de dois funcionários da Secretaria Estadual de Saúde (RS): o funcionário público do Estado Marco Antônio Lucaora ${ }^{30}$ e a enfermeira Rita Sosnoski Camello que, na primeira fase da concepção do memorial, estiveram em diálogo com os funcionários Neusa Maria de Oliveira Barcelos, coordenadora do Serviço de Memória e Cultura do HPSP; Edson Medeiros Cheuiche, historiador do HPSP; Lia Conceição Mineiro de Souza Magalhães, assessora de comunicação social da Direção Central dos Hospitais Estaduais (DCHE); e Dennis Guedes Magalhães, assessor de comunicação social do DCHE.

$\mathrm{Na}$ ocasião em que Marco teve a ideia de criar um memorial no local, ele havia se dirigido ao $\mathrm{HCl}$ para recolher documentos, dos hospitais do Estado: "Hospital psiquiátrico São Pedro, Itapuã, Dermatologia Sanitária,e mais o Sanatório Partenon, e levar tudo para o Museu da Medicina [...]"(Informação verbal ${ }^{31}$ ) Entretanto, ao chegar no $\mathrm{HCl}$ Marco foi sensibilizado pelo lugar e o seu objetivo mudou: "Eu estava querendo mostrar o sofrimento, a angústia de tudo o que eles passaram [...]. É a história deles. Com 17, 18 anos, tirado do meio da tua família pra nunca mais voltar..." (idem). Assim, a concepção que motivou Marco estava impregnada pela intenção de transmitir a experiência de quem viveu o isolamento. Além da preocupação de tornar pública essa dimensão subterrânea do passado, a narrativa de Lucaora também reflete a natureza ambígua dos hospitais-colônia, quando afirma que o

\footnotetext{
${ }^{29}$ Quase sempre, porque há eixos expositivos, como a sala "A história da lepra no mundo" e a sala que rende homenagem à comunidades do entorno, por exemplo, que não fazem parte do cotidiano comuntário da colônia. ${ }_{30}$ Marco Lucaora fez da paixão pela arte um ofício, sendo reconhecido no seu meio profissional como um artista plástico. Diante disso, desempenha diversas ações de restauro, recuperando objetos dos hospitais estaduais. 31 Informação fornecida por Marco Lucaora durante entrevista concedida à Daniele Borges Bezerra, no $\mathrm{HCl}$, em 11 de mai de 2015.
} 
dispositivo de isolamento criado "pra que eles tivessem todo o conforto e toda estrutura" era ao mesmo tempo projetado "para que eles não saíssem" (idem).

Já, a concepção da enfermeira Rita, lepróloga que trabalha no $\mathrm{HCl}$ desde 2007, está permeada pelas suas experiências profissionais, dentre elas no Programa Estadual de Controle da Hanseníase (RS), onde foi responsável pela capacitação e a supervisão de profissionais da saúde. O trecho a seguir reforça o ponto de vista da idealizadora, com relação à memória institucional do $\mathrm{HCl}$ : "a saúde pública teve uma grande relevância no período 30-50. Grandes investimentos. Devemos sim preservar a memória da saúde, das pessoas, bem como da arquitetura" (informação verbal ${ }^{32}$, grifos nossos). Suas palavras transparecem a grandiosidade atribuída à saúde neste contexto de reconhecimento. Assim, a concepção do Memorial $\mathrm{HCl}$, na perspectiva da enfermeira Rita, que ficou responsável pelo agendamento dos grupos e pela realização das visitas guiadas, leva em conta a preservação do passado institucional sob um viés histórico, mas também o considera como recurso, como um veículo de informação que pode servir ao presente.

Em entrevista Rita afirma:

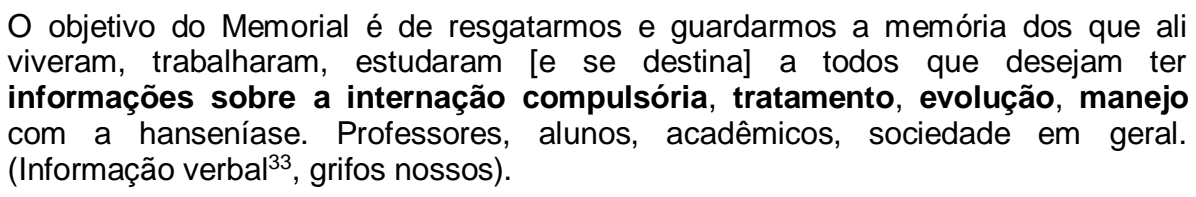

Observa-se que, devido ao seu comprometimento com a difusão do conhecimento sobre a doença, a enfermeira fez do Memorial um recurso pedagógico, um veículo de informação estratégico em termos de saúde pública. Nesse sentido, a palestra, que ocorre antes do percurso guiado, sensibiliza os visitantes sobre o passado e serve como brecha para a transmissão de informações que permitem identificar precocemente a doença. A narrativa, que conta a história da doença e alerta para os seus riscos no presente, também mobiliza nos visitantes sentimentos de empatia, relacionados ao sofrimento físico e emocional pelos quais as pessoas afetadas pela doença passaram. Como única narradora do espaço, algumas vezes a enfermeira toma a palavra em nome dos moradores: "Dona Rita, ter lepra é ter o pecado que a sociedade não pode perdoar, com isso repele,

\footnotetext{
32 Informação fornecida por Rita Camello através de entrevista, após visita ao Memorial HCl ocorrida em março de 2016. A interlocutora pediu que as questões fossem enviadas por email e as respostas foram recebidas em 10 de mai de 2016.

${ }^{33}$ Informação fornecida pela interlocutora Rita Camello, idem.
} 
marginaliza e crucifica". Isso é uma fala de um dos nossos moradores" (Informação verbal $^{34}$ ). Infelizmente não há ainda no memorial narrativas orais ou escritas dos moradores,em primeira pessoa, aos quais os visitantes possam ter acesso.

Com relação à mensagem transmitida durante a palestra, a enfermeira Rita deixa subentendido que a tecnologia de isolamento não foi a causa do sofrimento, mas sim a experiência de adoecimento, num meio social marcado pelo preconceito, o que de fato se confirma em muitos relatos de antigos moradores. Entretanto, do modo como o preconceito é descrito em sua fala ele parece ser, justificável diante da gravidade dos sintomas, numa época em que a cura era desconhecida. É o que se retém da narrativa que contextualiza as pinturas utilizadas como recurso visual durante a palestra. No primeiro exemplo, que se refere à pintura do rei Balduíno $\mathrm{IV}^{35}$ a seguinte descrição é feita: "O rosto está todo carcomido. [...]. Agora vocês imaginam se essa criatura estivesse a cavalo, quem o obedeceria? Então, para ele poder reinar ele fez essa máscara e reinou até o fim da vida dele" (informação verbal ${ }^{36}$ ).

Neste outro exemplo a mesma apresentação do passado na forma de choque se repete:

Essa menina foi Miss Bergen. Ela foi a última paciente a internar e a última paciente a morrer. Foi miss aos dezoito anos, aos vinte descobriu que era leprosa e foi levada para o hospital. [...] Ela diz: "Não, o meu rosto ninguém vai ver". Aqui está [refere-se à pintura] a última paciente que morreu e ela deixou todo o rosto tapado, porque ela estava totalmente carcomida. Foi miss, e olha o que pode acontecer com um ser humano (informação verbal ${ }^{37}$ ).

Interpretações como esta, entoadas de modo performático, emocional, legitimadas pelo saber clínico, que expõe em minúcias a degeneração física, potencializam a percepção do estigma e o acontecimento da doença como tragédia. Os trechos narrativos apresentados neste contexto reforçam a delicada tarefa de tornar públicos passados difíceis como este. Sobretudo quando as pessoas implicadas neste passado ainda estão vivas e podem sentir-se desconfortáveis.

\footnotetext{
34 Trecho da narrativa da enfermerira Rita durante a palestra que antecedeu a visita guiada ocorrida no Memorial $\mathrm{HCl}$, em 08 de mar. De 2016.

35 O filme "Cruzada" de Ridley Scott (2005) é baseado na história deste rei.

${ }^{36}$ Informação verbal registrada durante a palestra ministrada pela enfermeira Rita Camelo durante visita com alunos da Escola de Saúde Pública, RS, ao Memorial HCl, ocorrida em 08de mar de 2016.

${ }^{37}$ Idem. Fala proferida pela enfermeira Rita Camello durante a palestra realizada na visita ao $\mathrm{Memorial} \mathrm{HCl}, \mathrm{com}$ alunos da Escola de Saúde Pública, em 08 de mar. de 2016.
} 
Com relação a ausência dos moradores no processo de transmissão das memórias, Marco Lucaora tem a opinião de que o memorial supre as demandas de qualquer visitante ou pesquisador, além disso, acredita que o contato com o morador seria inapropriado porque poderia gerar situações constrangedoras. Uma preocupação legítima, no tocante à privacidade dos moradores, que também diz respeito ao direito de esquecer. Entretanto, a dimensão ética do cuidado não pode ser confundida, nem aplicada, como tutela dos discursos. Nesse sentido, durante os encontros com os antigos moradores constatamos, como é comum nessa fase da vida, que o morador que chegou jovem ao espaço do antigo leprosário, hoje idoso, "desempenha uma função para a qual está maduro, a religiosa função de unir o começo ao fim, de tranquilizar as águas revoltas do presente alargando suas margens [...]" (BOSI, 2009, p. 82). Ou seja, no encontro com os moradores, a experiência preenche e estrutura o tempo na forma de narrativas (BENJAMIN, 1989, p. 129), um tempo que se observa no espaço pela aura, enquanto distância. Mas que para os últimos moradores do lugar é parte de uma experiência incorporada. (BENJAMIM, idem p.107). Nesse sentido, a ausência das narrativas em primeira pessoa no dispositivo memorial, quando os idealizadores se propõem a abranger as relações cotidianas dentro da colônia, constitui-se como uma fragilidade estrutural na transmissão do passado representado.

Assim, se de um lado a experiência no Memorial $\mathrm{HCl}$ é intensa, por outro é superficial. Isso porque a narrativa introdutória ao espaço, é extensa e formaliza um discurso institucional sobre o passado, mas a narrativa expositiva é caricatural. Além do que, o circuito é amplo e a quantidade de informação visual dificulta a atenção. Esse excesso de informação que se observa tanto pela acumulação de elementos díspares num mesmo contexto expositivo, como pela criação de cenários idealizados ou carregados de estereótipos, pode acarretar tanto na banalização da memória, como observou Régine Robin (2016), quanto na espetacularização do sofrimento (SONTAG, 2003), um dilema ético, errôneamente justificado pela intenção de promover o patrimônio por meio da sedução, do fetiche, ou pelo intuito de provocar a empatia fazendo do uso da dimensão dolorosa da memória um abuso (Cf. RICOUER, 2007, p.100).

Destarte, na primeria sala a que o visitante tem acesso após a palestra, o diorama, que representa "A história da lepra no mundo", produz um efeito de choque. A sensação diante do manequim é incômoda. Não há realismo, por mais que pareça ser este o objetivo das manipulações que levaram à reprodução do estigma no personagem envolto em trapos:

Revista Memória em Rede, Pelotas, v.11, n.20, Jan./Jun.2019 - ISSN- 2177-4129 
Então, nos trouxeram um manequim, nós o mutilamos e fizemos dele um Lázaro, que é aquela pessoa sem nariz, com os olhos totalmente rebaixados, com as mãos deformadas e os pés também. E ele vai morar num mato próximo a uma rua aonde ele possa esmolar. Então esta é a vida do lázaro no período em que tudo é pecado (Informação verbal ${ }^{38}$ ).

As emoções desagradáveis provocadas pelo Lázaro, como é chamado pelos idealizadores, estão associadas à degradação e à exclusão, experiências relacionadas ao adoecimento num tempo em que a cura era desconhecida e a doença entendida como uma falha moral ou um castigo divino. Então, embora o cenário vivido pelos moradores do $\mathrm{HCl}$ não tenha sido o mesmo, o estigma, difícil de desvincular da própria identidade, ainda ressoa entre aqueles que passaram pelo isolamento compulsório e convivem com o fantasma do preconceito. Nesse sentido, a exposição caricatural que "acompanha a construção das identidades" (CANDAU, 2011 p.163), como uma forma de domesticação das memórias, nem sempre é benéfica para as pessoas implicadas nessa construção narrativa.

Chama-se atenção, com isso, para o risco inerente às narrativas dos espaços museais, que, enquanto interpretações do passado, são seleções incompletas que conduzem ideologias e refletem o arcabouço cultural de quem as formula. Por outro lado, quando fazem emergir o sentido de comunidade, ou quando envolvem a comunidade em seus processos de elaboração, estes dispositivos de transmissão da memória podem fornecer um sentido de coesão aos grupos e produzir entre os seus membros a sensação de "destino compartilhado" (CANDAU, ano p.107).

Ao conversarmos com os moradores sobre o $\mathrm{HCl}$, as narrativas não demonstraram o envolvimento dos mesmos no processo de criação do Memorial $\mathrm{HCl}$, embora alguns tenham emprestado fotografias dos seus acervos pessoais para que fossem digitalizadas e expostas na "Sala dos amores", a sala dedicada aos casais. É o que se depreende da fala da Sra Alice: "Isso aqui tudo foi o fulano que levou pra bater foto e depois não foi colocado no plástico e ficou essas falhas [no álbum].(Informação verbal ${ }^{39}$ ). E da fala do Sr. Pedro: - Sim, aquelas fotos foram doadas. Mas eu tenho algumas fotos que têm futebol [...] (Informação verbal $\left.{ }^{40}\right)$. E, ainda, dona Alice: "É, as fotos que nós tínhamos eles levaram. Foi lá pro memorial, né? Bem no canto, bem nos fundos. Perto da noiva." (Informação verbal ${ }^{41}$ ).

Ao falarmos sobre o memorial com a Srạ . Valdeci a mesma afirma:

\footnotetext{
38 Trecho da narrativa da guia durante visita guiada no Memorial $\mathrm{HCl}$ em 08 de mar. de 2016.

${ }^{39}$ Narrativa da moradora Alice, durante entrevista narratica com Daniele Borges Bezerra, em jan. de 2017.

40 Narrativa do morador Pedro, durante entrevista narratica com Daniele Borges Bezerra, em jan. de 2017

${ }^{41}$ Narrativa da moradora Alice, idem.
} 
Olha, de lá do memorial eu só tenho na minha memória as fotos do meu marido, que não era meu marido ainda, quando era solteiro, e fotos do meus vizinhos, do Fulano, da Ciclana, Beltrano- que já se foi - uma porção de gente antiga que eu conheci. Ora sessenta anos dá pra conhecer, né? (Informação verbal ${ }^{42}$ ).

O Sr. Pedro, que parecia inibido ao emitir sua opinião sobre o lugar,disse quase sem nenhuma emoção: "Gostei, gostei. Ta muito bem enfeitado. É bom, né? Ta representando alguma coisa." (Informação verbal| ${ }^{43}$ ). Já, Leonora, que expressa grande preocupação com o destino da colônia: "Morro de tristeza de ver tudo caindo [...]" (Informação verbal ${ }^{44}$ ), nunca visitou o memorial. E, ainda, quando retomamos o assunto para investigar a sua participação no processo de criação do memorial, ela diz: "Eu não tinha nada, não dei nada. Não! Eu acho que eles não devolviam. Aí não. Essas aqui [fotos de seu acervo pessoal] é pra recordação, enquanto eu viver" (idem).

O casal, Alice e Carlos, discorda da escolha expográfica da sala "A história da lepra no mundo", conforme narrativa que segue:

Dona Alice: - Aquela imagem ali [...] Olha, tem uma paciente daqui, a Maricota, a Maricota nunca entrou lá, por causa daquilo ali. Eu digo: "pra que botar, logo na primeira porta, na entrada ali, botar aquela figura?" Ah, diz: "Do passado antes de Cristo" [desdém] Sei lá, aquilo lá. Pra que botar aquilo lá. Tu viu, né?

Sr. Carlos: -Exagero, exagero naquela imagem que fizeram ali.

Dona Alice: - Bom tu viu, né? É um espanto.

Sr. Carlos: - Exagero, exagero, muito exagerado.

Com isso, ao apresentar apenas o estereótipo medieval, sem incluir outras manifestações do fenômeno no tempo e no espaço, tem-se a sensação de que a escolha expositiva pode reforçar o estigma associado à doença, conforme observado pela SrªAlice, antiga moradora, referindo-se ao Lázaro: "Achei negativa! Pra que? Ai, ainda, no dia da inauguração veio uma porção de colégio, a entrada era tudo ali. Pra que essas crianças verem isso? Aquilo ali assusta quem nunca viu. Porque as pessoas não chegaram a viver isso dessa forma, aqui" (Informação verbal| ${ }^{45}$ ). Além de demonstrar desconforto diante de um estereótipo que não foi experimentado por eles, e que está sendo associado a eles, a moradora preocupa-se com as consequências da exposição desse imaginário às crianças que visitam o memorial. E o marido complementa: "Já assustam logo de cara, na primeira

\footnotetext{
42 Narrativa da moradora Valdete durante entrevista narratica com Daniele Borges Bezerra, em jan. de 2017.

${ }^{43}$ Narrativa do morador Pedro, idem.

44 Narrativa da moradora Leonora, durante entrevista narratica com Daniele Borges Bezerra, jan. de 2017.

${ }^{45}$ Narrativa da moradora Alice, durante entrevista narrativa com Daniele Borges Bezerra em jan. de 2017
} 
sala" (Informação verbal| ${ }^{46}$ ). "Ai, nem era pra ter aquela figura" (Informação verbal ${ }^{47}$ ), replica a esposa.

Em contrapartida, na Sala dos amores, a narrativa memorial construída para o vestido da noiva tenta humanizar não apenas o objeto, mas a vida em isolamento, através da incorporação de presenças ancoradas nas fotografias dos casais, "recuperando" momentos felizes. A humanização do objeto é conduzida, de tal modo pela guia, idealizadora do memorial, que o transforma num quase ente. Pois, as narrativas associadas ao vestido de noivas e ao travesseiro, da sala ao lado, são pensadas para enfatizar uma relação afetiva entre os moradores e os objetos no tempo. Nestes casos, os objetos tornamse depositários de um tempo fixado pela costura: "O vestido era feito e refeito de acordo com a necessidade da próxima noiva a se casar"(informação verbal ${ }^{48}$ ). Já, a palavra "felicidade" teria sido bordada por uma menida de 6 anos, segundo relato de um dos idealizadores do Memorial $\mathrm{HCl}$ ao Jornal Gaúcha $\mathrm{ZH}$, que promoveu a matéria intitulada "Acervo de Dores e amores", da qual destaca-se o seguinte trecho:

Bordada à mão por uma interna de seis anos, a capa permanece intacta há sete décadas. A pequena bordadeira, que odiava o sol e detestava flores amarelas por ter chegado a Itapuã usando um vestido dessa cor, bordou no pano branco com traços nas cores rosa e verde uma palavra [felicidade] cujo significado desconhecia. Não sabia ler e escrever quando chegou à instituição. (CUSTÓDIO, 2017 ${ }^{49}$ ).

Nesse processo de "fabricação do passado" (BONNIOL In BENSA; FABRE, 2001) que caracteriza o preenchimento das lacunas temporais de narrativas, que se pretendem históricas, as "zonas de sombra" (idem, p.179) são geralmente preenchidas com a construção de um imaginário que se nutre de afetos inventados, com o objetivo de tornar consumíveis as memórias. O que corrobora com a fala do antropólogo Joel Candau quando afirma que os processos de domesticação do passado, como uma forma de torná-lo organizado, compreensível, transmissível, são sobretudo uma forma de apropriação (CANDAU, 2006, p.117).

À vista disso, as narrativas produzidas pelos espaços museais, enquanto interpretações do passado, são apropriações condutoras de ideologias que refletem os interesses de quem as construiu. O que pode ser entendido, como uma pretensão de auto celebração, conforme propõe o autor: "De um modo geral a comemoração oficial pretende

\footnotetext{
${ }^{46}$ Narrativa do morador, Carlos, durante entrevista narrativa com Daniele Borges Bezerra em jan. de 2017

47 Narrativa da moradora Alice, idem.

48 Trecho da narrativa da guia durante visita guiada no Memorial $\mathrm{HCl}$ em 08 de mar. de 2016 .

49 Informação veiculada na matéria: Acervo de dores e amores, publicada em: 26 de out. de 2017. Disponível em: <http://especiais.zh.clicrbs.com.br/especiais/zh-singular/viamao/>.
} 
ser [...] uma auto celebração organizada de maneira tal que o passado e a memória não podem questionar o presente (CANDAU, 2006, p. 70). O que nos coloca diante da dimensão ausente das narrativas, que pode passar despercebida dada a autoridade atribuída aos dispositivos oficiais, quando se propõem a preencher todas as lacunas do passado, negligenciando seus silêncios. Isso deve estar claro, caso tenhamos em mente uma conciliação entre história e memória, pois, como afirma Octave Debary (2015, p.5, tradução nossa ${ }^{50}$ ) nesse equilíbrio reside a "diferença entre uma memória apaziguada e uma memória falsificada".

\section{Considerações finais}

Observa-se que a musealização, com a criação de dispositivos memoriais e o arquivamento do passado, nem sempre leva à transmissão, pois o arquivo possui a dupla natureza de conservar e esconder. E, como alguns "[...] museus são feitos para esquecer" (BECKER; DEBARY, 2012, p.9, tradução nossa ${ }^{51}$ ) alguns arquivos permanecem ocultos ou nascem para ocultar (Cf. DERRIDA, 2001). Portanto, é preciso considerar o silêncio dos moradores no dispositivo oficial de memória criado pela instituição. Pois, apesar da indiscutível importância do Memorial HCl em "conservar os restos" (DEBARY, 2002) de um passado em fase de desaparecimento na Colônia Itapuã, é necessário estar atento à domesticação dos discursos que esvazia a memória de seu potencial de "rastro" (RICOUER, 2007).

Em síntese, é como se a narrativa do Memorial $\mathrm{HCl}$ afirmasse que o terrível sofrimento físico e emocional enfrentado pelas pessoas afetadas pela hanseníase tenha encontrado conforto na vida proporcionada dentro da Colônia Itapuã, de tal maneira que no discurso oficial da instituição sobre o passado, os empreendimentos da saúde tornam-se louváveis e a instituição cumpre uma função heroica. Por isso, antes de mais nada, o Memorial $\mathrm{HCl}$ configura-se como um dispositivo memorial que aborda a história do $\mathrm{HCl}$, sem escapar de sua ambiguidade. De sorte que, os valores atribuídos à tecnologia da saúde confundem-se com os valores do exótico e do ordinário, mas também com os valores afetivos e a ausência deles, ambos relacionados à construção de uma narrativa que

50 "Différence entre une mémoire apaisée et une mémoire falsifiée".

51 "[...] musées sont faits pour oublier". 
transforma a experiência do isolamento compulsório em memória domesticada de uns, memória heroica de outros.

\section{Referências}

BRASIL. Lei 9.010 de 29 de março de 1995. Disponível em:

http://www.planalto.gov.br/ccivil_03/leis/L9010.htm. Acessado em 20 de abril de 2017.

Decreto no 968, de 7 de maio de 1962. Baixa normas técnicas especiais para o combate à lepra no país e dá outras providências. Disponível em: <http://br.vlex.com/vid/baixa-tecnicas-especiais-combate-lepra-pais-34143129>. Acessado em 10 de abril de 2014.

BONNIOL, Jean- Luc. Le fabrique du passé: Le Larzac entre mémoire, histoire ET patrimoine. BENSA, Alban; FABRE, Daniel. Une histoire à soi: figurations du passe et localités. Éditions de la Maison dês sciences de I’homme. Paris: 2001.

CANDAU, Jöel. Memória e identidade. Traduzido por: Maria Leticia M. Ferreira. São Paulo: Contexto, 2011.

CUSTÓDIO, Aline. Acervo de dores e amores. GaúchaZH. 26 de out. de 2017. Disponível em: <http://especiais.zh.clicrbs.com.br/especiais/zh-singular/viamao/>.

DEBARY, Octave. La fin du Creusot ou L'art d'accommoder les restes. Paris: Éditions du CTHS, 2002, Collection Le regard de l'ethnologue 13, 189 p. Disponível em: www.microsillons.org/collection/CreusotDebary.pdf. Acessado em 10/03/2015.

FOUCAULT, Michel. História da loucura. 6ํㅡ. Ed. São Paulo: Perspectiva, 2000.

FUNARBE. Conjunto Urbano da Colônia Santa Izabel: Dossiê de tombamento.Betim, MG, 1998. Disponível em: $<$ http://www.betim.mg.gov.br/patrimoniocultural/bens_tombados_e_inventariados/Dossie\%2 0Colonia\%20Sta\%20lzabel.pdf>. Acessado em 14 de fevereiro de 2017.

GOFFMAN, Erving. Manicômios, Prisões e Conventos. São Paulo: Ed. Perspectiva, $7^{\text {a }}$ ed., 2003.

Estigma: Notas sobre a manipulação da identidade deteriorada. 4 ed. Rio de Janeiro: Guanabara, 1988.

GUILLAUME, Marc. A política do patrimônio. Porto: Tipografia do Carvalhido, 2003. HALBWACHS, Maurice. Los marcos sociales de la memoria. Traduzido por: Manuel A. Baeza y Michel Mujica. Barcelona: Anthropos editorial, 2004.

A memória coletiva. São Paulo. Edições Vértice, 1990.

IGNATIEFF, Michael. Instituições totais e classes trabalhadoras: Um balanço crítico. Revista brasileira de História. São Paulo, v.7, no 14, 1987. Disponível em: < 
file:///C:/Users/Dani/Documents/Downloads/michaelignatieff.pdf $>$. Acesso em 01 de agosto de 2017.

IPHAE/RS, Instituto do Patrimônio Histórico e Artístico do Estado. Processo de tombamento: $\mathrm{HCl}$. Mensagem pessoal. Mensagem recebida por borgesfotografia@gmail.com em 10 de maio de 2017.

MORHAN. Cadernos do Morhan: Projeto Acervo: Pela recuperação e preservação dos registros históricos dos hospitais-colônia. Edição 6. 2010. Disponível em:

<http://www.morhan.org.br/views/upload/caderno_06_acervo_BAIXA.pdf > Acesso em 22 de mai. de 2017.

RADLEY. Alan. Artefacts, memory and a sense of the past. In Collective remembering: Inquiries in social construction series. London: Sage Publications, 1994.

RICOEUR, Paul. A memória, a história, o esquecimento. Tradução de Alain François [et al]. Campinas: Ed. Unicamp, 2007.

ROBIN, Régine. A memória saturada. Tradução: Cristiane Dias; Greciely Costa. Campinas: Editora da Unicamp, 2016.

SERRES, Juliane conceição Primon. Memórias do Isolamento: trajetórias marcadas pela experiência de vida no Hospital Colônia Itapuã. São Leopoldo:Unisinos, 2009. Tese de Doutorado do Centro de Ciências Sociais.

SERRES, Juliane Conceição Primon; BORGES, Viviane Trindade. Los museos em antigos leprosários y el sufrimiento: tendências, instituciones e actores sociales. Apresentado no 37 Simpósio do International Committee for Museology of the International Council of Museums (ICOFOM): "Novas tendências em museologia" em Paris, 5-9 junho 2014.

SERRES, Juliane Conceição Primon; BEZERRA, Daniele Borges. Hospital de emergência e Leprosário Itapuã no Rio Grande do Sul: Do isolamento ao esquecimento. História da hanseníase no Brasil. Laboratório de Estudo de Etnicidade, Racismo e Discriminação (LEER) Universidade de São Paulo- USP. E-book (No prelo).

UPPH/ SP, Unidade de Preservação do Patrimônio Histórico. Secretaria do Estado de São Paulo, Consulta de Processo de Bem tombado: Aimorés. Mensagem pessoal. Mensagem recebida por borgesfotografia@gmail.com em 14 de abr. de 2015.

O presente trabalho foi realizado com apoio da Coordenação de Aperfeiçoamento de Pessoal de Nível Superior - Brasil (CAPES) - Código de Financiamento 001. 